\title{
NEED OF LUTEINIZING HORMONE FOR EARLY PREGNANCY IN THE GOLDEN HAMSTER (MESOCRICETUS AURATUS)
}

\author{
A. JAGGANNADHA RAO, H. G. MADHWA RAJ AND \\ N. R. MOUDGAL

\begin{abstract}
Endocrinology Laboratory, Biochemistry Department, Indian Institute of Science, Bangalore-13, India
\end{abstract}

(Received 5th June 1970)

\begin{abstract}
Summary. Administration of LH antiserum to intact pregnant hamsters on any day from Days 6 to 11 of pregnancy resulted in termination of gestation. Following LH antiserum injection, the ovarian weights were markedly reduced.
\end{abstract}

Hypophysectomy performed at any stage of pregnancy has been reported to be deleterious for maintenance of gestation in the hamster (Greenwald, 1967). On the basis of his observation that a combination of follicle stimulating hormone (FSH) and prolactin could maintain pregnancy in hypophysectomized pregnant hamsters, Greenwald (1967) suggested that the luteotrophic complex in this animal is made up of FSH and prolactin. Luteinizing hormone ( $\mathbf{L H})$, however, has been shown to promote progesterone synthesis in a wide variety of species including the rat (Kilpatrick, Armstrong \& Greep, 1964; Armstrong \& Black, 1966; Savard, Marsh \& Rice, 1965). Recently, it has been shown that neutralization of endogenous LH in the pregnant rat by administration of a highly specific LH antiserum results in termination of gestation in this species (Madhwa Raj, Sairam \& Moudgal, 1968; Madhwa Raj \& Moudgal, 1970). It was therefore considered of interest to study the effect of $\mathrm{LH}$ antiserum on pregnancy in the hamster. The following is a preliminary account of such a study.

Colony-bred hamsters, weighing 100 to $120 \mathrm{~g}$, were mated to proven males and the first day on which spermatozoa were found in the vagina was taken as Day 1 of pregnancy. Before starting the treatment, hamsters were subjected to exploratory laparotomy on Day 6 of pregnancy and only those which showed normal numbers of implantation sites were used for further experimentation. Autopsies were performed at various stages of pregnancy and the nature and number of implantation sites were noted.

The details of the immunization schedule and the characterization of the antiserum have been reported earlier (Madhwa Raj \& Moudgal, 1970). The rabbit antiserum to ovine $\mathrm{LH}$, absorbed free of antibodies to normal sheep serum proteins, could neutralize the LH activity of hamster pituitary extracts as assayed by the ovarian ascorbic acid depletion test. Incubation of undiluted $\mathbf{L H}$ antiserum with ${ }^{125}$ I-labelled highly purified ovine LH, FSH or prolactin resulted 


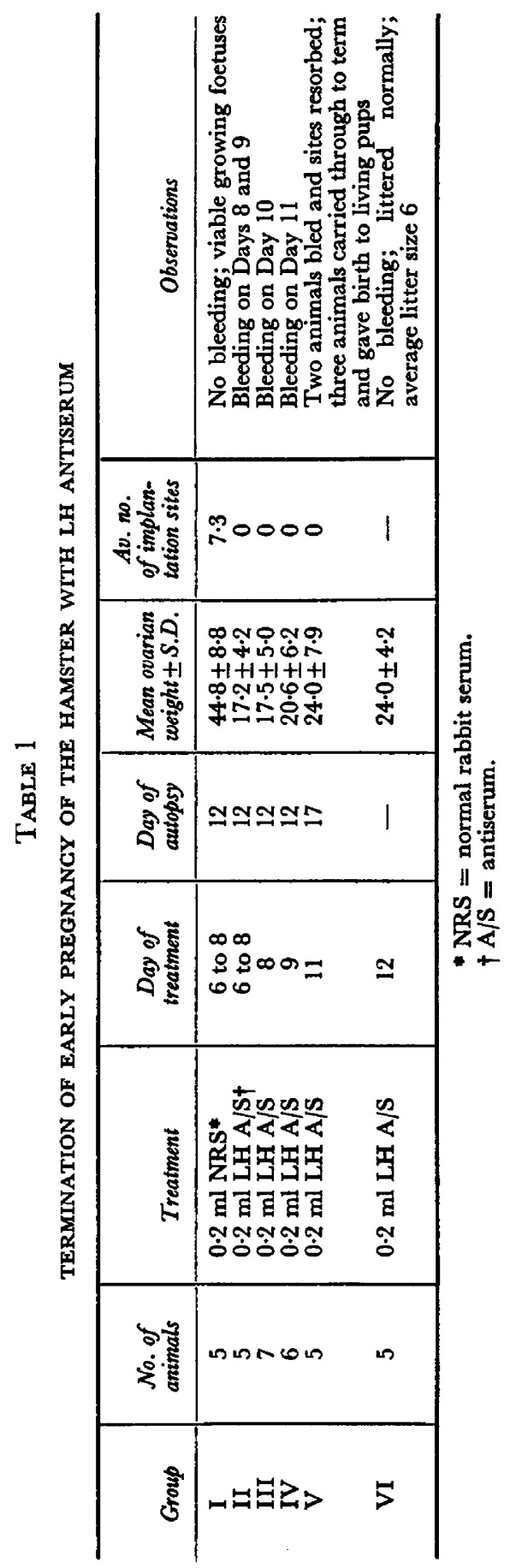


in binding with only the former, demonstrating, in addition to specificity, the lack of antibodies to the other two hormones. Antiserum was administered by the subcutaneous route.

The results presented in Table 1 show that pregnancy could be terminated by administration of the antiserum on one or more days from Days 6 to 10 . Vaginal bleeding was noted within 36 to $48 \mathrm{hr}$ of the injection of antiserum and subsequently no implantation sites were found at autopsy. Control animals treated with normal rabbit serum maintained normal pregnancy. When the antiserum was administered on Day 12, pregnancy was maintained in all the animals and they littered normally.

The present data suggest that the hamster resembles the rat in being dependent upon LH for the maintenance of gestation during the first 11 days of pregnancy. Since the antiserum used in the present study was seen to be highly specific in that it bound only ${ }^{125}$ I-labelled LH and not FSH or prolactin, its action on pregnancy cannot be attributed to non-specific effects. The ovarian weight of the pregnant hamster was reduced following the injection of $\mathbf{L H}$ antiserum and this effect was marked if the antiserum was given before Day 10. In a parallel study carried out in rats, a single injection of antiserum did not produce such a marked reduction in its ovarian weight, suggesting that the hamster ovary is much more sensitive than the rat to the lack of LH. Further work is in progress to characterize the rôle of $\mathrm{LH}$ in the luteotrophic complex necessary to maintain the structural and functional integrity of the corpus luteum and gestation of the hamster.

A gift of highly purified ovine LH and Fst by Professor C. H. Li and Dr H. Papkoff, Hormone Research Laboratory, University of California Medical Center, San Francisco, is gratefully acknowledged. The authors are also thankful to the Endocrine Study Section, N.I.H., Bethesda, Maryland, U.S.A., for a generous gift of ovine FSH and prolactin. Financial support for this study has been given by the Ford Foundation, New York, and the Indian Council of Medical Research, New Delhi.

\section{REFERENCES}

Armstrong, D. T. \& Black, D. L. (1966) Influence of luteinizing hormone on corpus luteum metabolism and progesterone biosynthesis throughout the bovine estrous cycle. Endocrinology, 78, 937.

Greenwald, G. S. (1967) Luteotropic complex of the hamster. Endocrinology, 80, 118.

Kilpatrick, R., ARMstrong, D. T. \& GreEp, R. O. (1964) Maintenance of the corpus luteum by gonadotrophins in the hypophysectomized rabbit. Endocrinology, 74, 453.

MADHWA RaJ, H. G. \& Moudgad, N. R. (1970) Hormonal control of gestation in the intact rat. Endocrinology, 86, 874.

Madhwa Raj, H. G., Satram, M. R. \& Moudgal, N. R. (1968) Involvement of LH in the implantation process of the rat. F. Reprod. Fert. 17, 335.

SAvARD, K., MARSH, J. M. \& RICE, B. F. (1965) Gonadotropins and ovarian steroidogenesis. Recent Prog. Horm. Res. 21, 285. 